\title{
Population profiling in China by gender and age: implication for HIV incidences
}

\author{
Yuanyi Pan* and Jianhong Wu
}

\author{
Address: Centre for Disease Modeling, Department of Mathematics and Statistics, York University,Toronto, Ontario, Canada \\ Email: Yuanyi Pan* - yuanyi@mathstat.yorku.ca; Jianhong Wu - wujh@mathstat.yorku.ca \\ * Corresponding author
}

Published: 18 November 2009

BMC Public Health 2009, 9(Suppl I):S9 doi: I0.1 I86/I47|-2458-9-SI-S9

This article is available from: http://www.biomedcentral.com/I47I-2458/9/SI/S9

(C) 2009 Pan and Wu; licensee BioMed Central Ltd.

This is an open access article distributed under the terms of the Creative Commons Attribution License (http://creativecommons.org/licenses/by/2.0), which permits unrestricted use, distribution, and reproduction in any medium, provided the original work is properly cited.

\begin{abstract}
Background: With the world's largest population, HIV spread in China has been closely watched and widely studied by its government and the international community. One important factor that might contribute to the epidemic is China's numerous surplus of men, due to its imbalanced sex ratio in newborns. However, the sex ratio in the human population is often assumed to be $\mathrm{I}: \mathrm{I}$ in most studies of sexually transmitted diseases (STDs). Here, a mathematical model is proposed to estimate the population size in each gender and within different stages of reproduction and sexual activities. This population profiling by age and gender will assist in more precise prediction of HIV incidences.
\end{abstract}

Method: The total population is divided into 6 subgroups by gender and age. A deterministic compartmental model is developed to describe birth, death, age and the interactions among different subgroups, with a focus on the preference for newborn boys and its impact for the sex ratios. Data from 2003 to 2007 is used to estimate model parameters, and simulations predict short-term and long-term population profiles.

Results: The population of China will go to a descending track around 2030. Despite the possible underestimated number of newborns in the last couple of years, model-based simulations show that there will be about $\mathbf{2 8}$ million male individuals in 2055 without female partners during their sexually active stages.

Conclusion: The birth rate in China must be increased to keep the population viable. But increasing the birth rate without balancing the sex ratio in newborns is problematic, as this will generate a large number of surplus males. Besides other social, economic and psychological issues, the impact of this surplus of males on STD incidences, including HIV infections, must be dealt with as early as possible.

\section{Background}

HIV/AIDS spread in China has been an increasingly growing concern since the first AIDS case was reported in Beijing [1]. When a joint assessment by the Chinese government, UN and WHO suggested in 2005 [2] that there were 650,000 individuals living with HIV/AIDS and 75,000 had developed AIDS, some claim that future incidence could rise up to $10-15$ million cases by 2010 [3]. With the largest population in the world, China must maintain and strengthen its efforts to control the epi- 
demic including raising awareness and prevention of the disease among risk groups: injecting drug users (IDUs), former plasma donors, men who have sex with men (MSM), sex workers, etc. Another possible high-risk group that is rarely studied is the surplus men. According to a study by J.D. Tucker and colleagues in 2005 [4], most people in this group are young, unmarried, poor, unemployed and less educated and are therefore more likely to turn to sex workers; consequently, the number of sex workers is likely to be increased due to the sexual demand from surplus men. Both factors increase the average sexual partner exchange rate, and a higher partner exchange rate normally leads to a larger HIV incidence rate [5].

However, sex ratio in the human population is often assumed to be 1:1 in most studies of sexually transmitted diseases (STDs). More specifically, the population is generally divided into certain subgroups based on gender, sexual behaviour and stage of disease development; the change rate of population in each subgroup is often assumed to be a function of the natural population growth, the nature of disease and the size of all other groups; the natural growth of the human population is usually believed to be proportional to the size of total population [5-9] (and references therein); and the sex ratio is balanced. This is normally true for a society with a stable age structure. But it is different for countries with rapid social and economical changes. For example, according to United Nation [10], the male population in China in the sexually active stage will decrease from $29 \%$ in 2000 to $23 \%$ in 2030 , while the sex ratio in the same group will increase from 1.066 to 1.12 .

There are many problems that might be caused by gender imbalance, such as antisocial behaviour and violence threatening the social stability, women trafficking and expansion of the sex industry [11]. Another major issue that deserves serious attention is the impact of gender imbalance on the spread of STDs, especially those STDs such as HIV/AIDS with long incubation periods and with different stages of disease progression.

Although a study proposed by T. E. Senn et al. [12] suggests that there is no association between the sex ratio and the number of sexual partners in African Americans, it is commonly believed that the surplus men will turn to sex workers for sexual service, especially when they cannot afford regular sex partners [4]. A. Ebenstein and E. Jennings in 2008 [13] found that most counties with a high rate of single men tend to be regions with a high rate of men paying for sex. They also claimed that $9 \%$ of men will pay for sex in 30 years, rising from $6 \%$ in 2005, partially because of the increasing number of unmarried men. Other reasons for the ascending trend of commercial sex activity include various social and cultural changes driven by economic reform since 1976 . The high rate of men purchasing sex seems to be occupation related. In [13], the authors noted the relationship between the percentage of men working in the construction industry and the prevalence of commercial sex activity. Other relevant studies include the work of B. Wang et al. [14] and a report by R. Zhao et al. [15]. The former found $10 \%$ of a total of 1,304 rural-to-urban migrant men paid for sex; the latter claimed that $9.4 \%$ of 232 miners in townships of Yunnan province purchased sex, while $9 \%$ of Chinese men in a similar age range purchased sexual services [16]. Regardless of the different focuses of these studies, all authors seem to agree that male clients of female sex worker in China need to be studied more, given the high rate of HIV/AIDS infection and its role of bridging the high-risk groups and the general population in the HIV/AIDS transmission. When surplus men become surplus clients [17], HIV/AIDS incidences may rise rapidly.

The disproportionate surplus men may also increase homosexual activities. Although there is no solid evidence as far as we know that suggests surplus men in China have higher level of homosexual behaviours than other demographic groups, especially when the sex service is sufficiently supplied by female sex workers, it is wildly believed that homosexual behaviours are common in certain male concentrated places like prison [18] and the army [19]. Nevertheless, the general public may become more tolerant to homosexual behaviour and more hidden homosexuals may publicly express their sexualities [11]. Since unprotected same-sex behaviour is well known for its high risk in spreading HIV/AIDS [20], an extraordinarily off-balanced male population may contribute to the increase of HIV/AIDS in the future. It is therefore important to make accurate predictions of the profile of populations in terms of gender and stages of sexual activities. This is certainly a very difficult task. For example, the UN claimed in 1951 that the world population in 30 years would be $2.976-3.636 \times 10^{9}[21]$ but it was $4.45 \times 10^{9}$ in 1980. We note that the 1986 UN estimation of the world population $6 \times 10^{9}$ in 2000 [22] was close to the actual number, $6.1 \times 10^{9}$. Predicting the population in countries such as China is certainly no less challenging, though some efforts have been made [23-26].

One factor contributing to the difficulty in predicting the population is the fast-growing economy. In less than 30 years, China has increased its Gross Domestic Product (GDP) from 364.52 billion yuan in 1976 to $21,087.1$ billion yuan in 2006. GDP index per capita in 2006 is almost 10 times that of 1976 [27]. The skyrocketing economy brought Chinese people a better life, as well as a lower birth rate that has been observed in developed countries during their development (Figure 1). The negative correlation between economic success and population growth is 


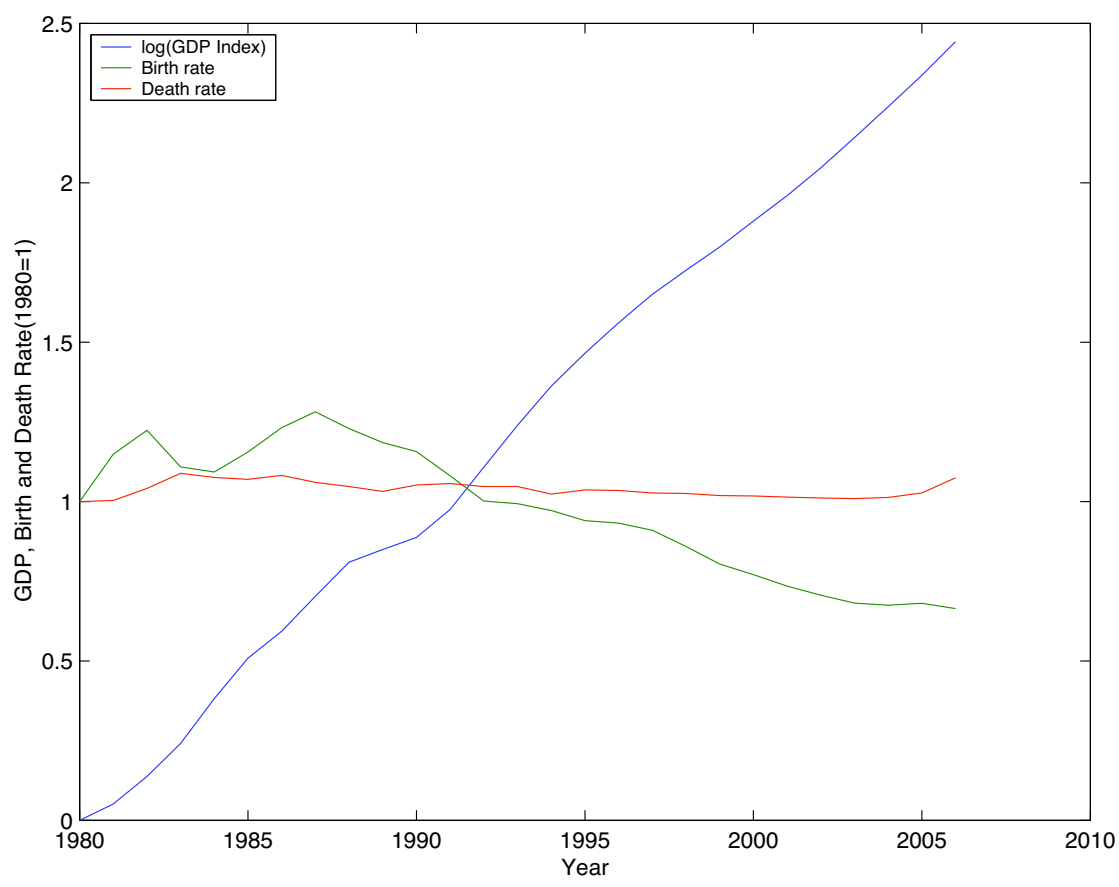

Figure I GDP index, birth rate and death rate in China. Source: Statistics China [27].

probably due to the trade-off between quantity and quality of children $[28,29]$. It would be difficult to use this correlation alone to predict the population in China, since not only the quality of raising children but also the rate of consumption of other commodities is expected to be different in coming decades.

Another reason that we should not consider the number of children just as a function of economy is the China's unique one-child policy. In 1970s, China's leaders worried that its swelling population could consume any effect to improve the quality of Chinese people's life. This worry was based on Malthusian Theory [30], which argues that population grows geometrically and that the food supply increases only at an arithmetic rate. Famine is hence inevitable unless constraints are applied to population growth. A planned-birth policy was introduced in 1973 and the one-child-per-couple policy became a national law in 1980 [31]. Although certain exceptions exist among ethnic minorities and in rural areas [32], most couples in China only have one child. Adding to the difficulty of predicting the population size in China is the abnormal gender imbalance among newborns. It is reported, for example, by Statistics China, that the average male-female ratio was 121.8 from 2003 to 2007 [27].

In this study, we compartmentalize the total population into 6 sex-age subgroups. The age structure is explicitly introduced because of a possible unstable age structure in the coming decades illustrated in Figure 2. A possible reason for the changing age structures is the comparatively large variance in the birth rate back in 1980s and 1990s, as shown in Figure 1. Our model incorporates the sexratio imbalance in newborns. Although this ratio is normally around 1.05 in a large population [33], China has a much higher sex ratio: 1.15 estimated by the UN [10]; data from Statistics China is even more dramatic [27]. A similar phenomenon seems to have been reported in India (1.08), Mauritania (1.08) and South Korea (1.1). Fertility decline and son preference are wildly believed to be two main reasons [34] to select sex in birth. Li et al. [35] established some quantitative relations among sex ratio at birth, fertility, and son preference. China, as one can imagine, has the worst scenario due to the one-child-policy and its long-lasting son preference [36].

Existing studies of the population size with consideration of gender imbalance include the work of Yellin et al. [37], where a dynamic system with three compartments - single individuals with two sexes, $N_{1}$ and $N_{2}$, and married couples, $T_{3}$ - is constructed. A match function with variables $N_{1}$ and $N_{2}$ was introduced in order to estimate the new cases in $T_{3}$. Our study differentiates from the aforementioned work by considering the rate of newborns as a function of the sizes of sexually active male and female populations. This is described by our proposed matching function, that needs to incorporate the so-called minimum viable population (MVP) in order to avoid the sin- 

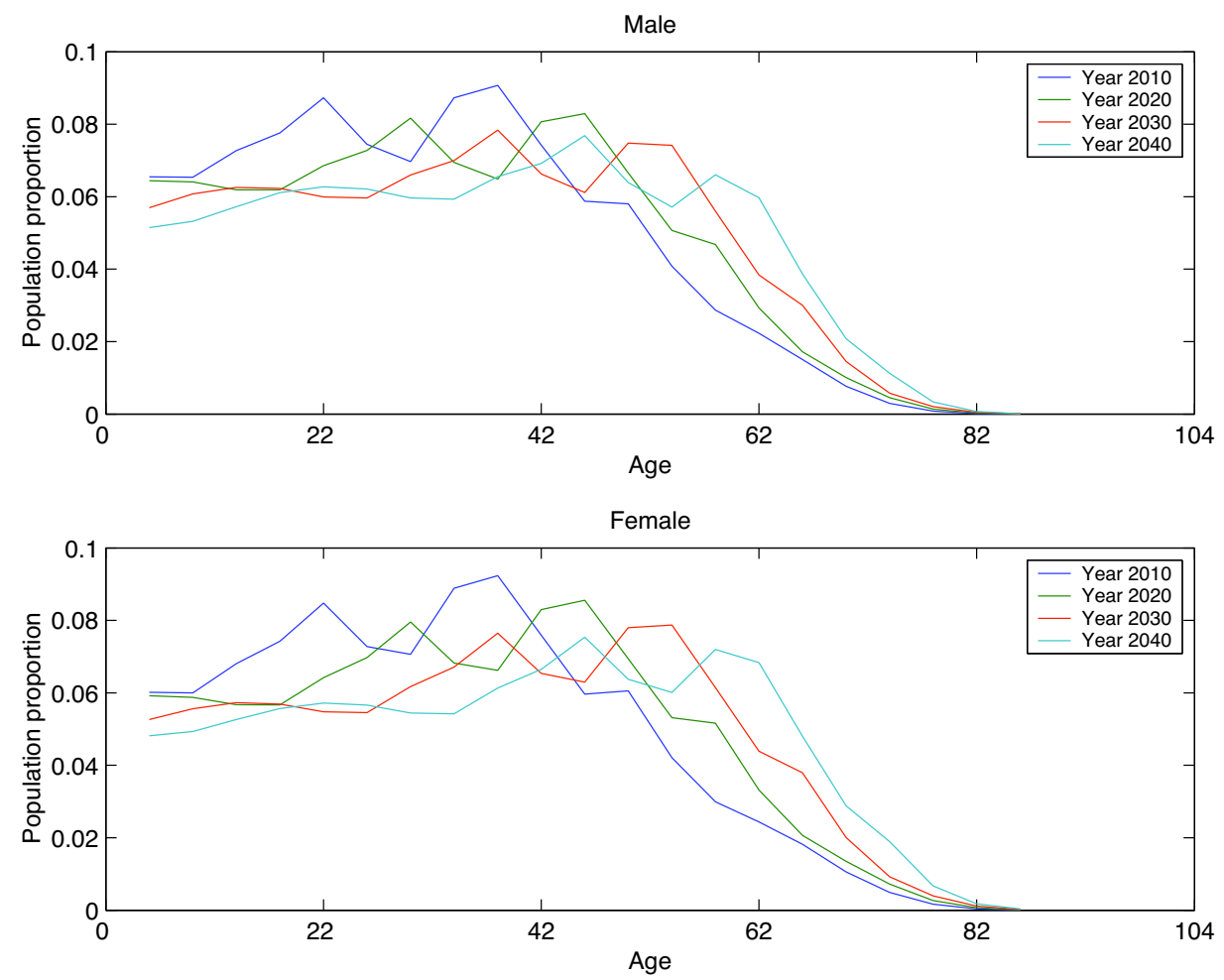

Figure 2

Age structure of male and female in China. Source: UN [10].

gularity at the trivial equilibrium state. Such an MVP size was introduced in [38-40] to represent the minimum number of individuals in a population in order for the species under consideration to survive.

\section{Methods}

\section{Mathematical model}

The total population is divided into 6 subgroups determined by gender (Male (M) and Female (F)) and stage of ages (stage 1: age 0 to age 14 ; stage 2: age 15 to age 49; and stage 3: age 50 and beyond). The second group will be important for reproduction and sexually transmitted infections. The sizes of these subgroups will be denoted by $M_{1}, M_{2}, M_{3}, F_{1}, F_{2}, F_{3}$, respectively. For example, $M_{2}$ is the size of the male population aged 15 to 49 .

The population change of each subgroup is the number of individuals entering minus those leaving this subgroup. More specifically, the inflow to stage 1 is due to the birth of newborns, while the inflow to and the outflow from stages 2 and 3 are due to aging and death. Note that people only leave age group 3 due to death.

The number of newborns is determined by a matching function $C:=C\left(M_{2}, F_{2}\right)$, similar to the match function introduced in [37], of the populations in stage 2 in both genders. It is natural to require the following properties of the matching function:

- $C\left(M_{2}, F_{2}\right)=0$ if either $M_{2}=0$, or $F_{2}=0$, or both;

- $C\left(M_{2}, F_{2}\right)$ is an increasing function of either variable if another is fixed;

- $C \propto M_{2}$ if $F_{2}{ }^{-} M_{2}$, and $C \propto F_{2}$ when $M_{2}{ }^{-} F_{2}$.

Two obvious functions satisfying the above properties are $C \propto \min \left(\mu_{M} M_{2}, \mu_{F} F_{2}\right)$ and $C \propto \frac{M_{2} F_{2}}{\mu_{M} M_{2}+\mu_{F} F_{2}}$ where $\mu_{M}$ and $\mu_{F}$ are the average number of reproductive partners that one individual can have. In our simulations, we choose the second one due to its smoothness. In this case, since monogamy is still the main marriage system in the modern society, we assume that $\mu_{M}=\mu_{F}=1$.

The above function has a singularity at the equilibrium when $M_{2}=F_{2}=0$. On the other hand, as stage 2 in our model is responsible for reproduction, it is natural to assume a minimal size must be maintained at this stage. Following the theory of minimum viable population 
(MVP) (see [38-40]), we will use the modified function $C \propto \frac{M_{2} F_{2}}{M_{2}+F_{2}+\dagger}$, where is a small positive number: the specific value of is not important for our simulations and analysis, as long as it is relatively small. This implies that $C\left(M_{2}, F_{2}\right) \approx 0$ if $M_{2}+F_{2} \ll$. Furthermore, the population growth is limited by the carrying capacity [41] so that the reproduction rate decreases when the population size is greater than the capacity. Consequently, we will use the following matching function throughout the reminder of this paper:

$$
C \propto \frac{M_{2} F_{2}}{M_{2}+F_{2}+\dagger} \exp \left(-\frac{N}{K}\right)
$$

with $N$ being the size of the total population and $K$ relevant to the carrying capacity.

Therefore, the deterministic compartmental model for a population stratified by genders and ages is as follows:

$$
\begin{aligned}
& \frac{d M_{1}}{d t}=\sigma \mu \frac{M_{2} F_{2}}{M_{2}+F_{2}+\dagger} \exp \left(-\frac{N}{K}\right)-g_{M_{1}} M_{1}-d_{M_{1}} M_{1} \\
& \frac{d M_{2}}{d t}=g_{M_{1}} M_{1}-g_{M_{2}} M_{2}-d_{M_{2}} M_{2} \\
& \frac{d M_{3}}{d t}=g_{M_{2}} M_{2}-d_{M_{3}} M_{3} \\
& \frac{d F_{1}}{d t}=(1-\sigma) \mu \frac{M_{2} F_{2}}{M_{2}+F_{2}+\dagger} \exp \left(-\frac{N}{K}\right)-g_{F_{1}} F_{1}-d_{F_{1}} F_{1} \\
& \frac{d F_{2}}{d t}=g_{F_{1}} F_{1}-g_{F_{2}} F_{2}-d_{F_{2}} F_{2} \\
& \frac{d F_{3}}{d t}=g_{F_{2}} F_{2}-d_{F_{3}} F_{3} .
\end{aligned}
$$

\section{Parameters and their estimation}

A description of the model parameters, along with their values (to be used in our simulations) and relevant references, can be found in Table 1. Note that $\mu \frac{M_{2} F_{2}}{M_{2}+F_{2}+\dagger} \exp \left(-\frac{N}{K}\right)$ is the number of newborns per unit time. In our simulations, we estimate the value of $\mu$ and $K$ by using the nonlinear least square estimation (LSE) to estimate the model-generated numbers against the reported newborns in 2003, 2004 and 2005 (the initial value of $K$ comes from [42], and the initial value of $\mu$ is determined by taking the initial $K$ and other parameters in 2003). Note that, unless otherwise specified, values of other parameters are taken from [27].

\section{Results and Discussion}

Simulations based on our models show that China's population will decrease around 2030, which is consistent with the estimation from UN; see Figure 3. Other agreements include the changing trend of each age group and gender group, see Figure 4.

Assuming that the birth ratio and birth rate remain unchanged for the next 100 years, we examine how the China's population and its age-sex structure change in the future. We can see from Figure 5 that China's population will decrease around the year 2030. We can also see an aging China coming: a China with a shrinking population and with a larger portion of aged individuals.

The main motivation for this study is the sex imbalance; we will address the impact of this imbalance on the spread of STDs in a subsequent study. Our simulations show that there will be about 28 million male individuals in 2055 who will not have female partners during their sexually active ages (Figure 4). In China, these male individuals are called Guanggun, that is, bare branch. The social, economic and health issues caused by this subpopulation must be addressed.

Fixing $\mu$ (birth rate) and varying $\sigma$ (proportion of newborn males) (Figure 6 and Figure 7) illustrates how the high sex-ratio imbalance in newborns affects the population structure. Similar manipulations to $\mu$ are presented in Figure 8 and Figure 9. These figures show that $\sigma$ is less significant than $\mu$ in changing population size but it will tremendously deteriorate the sex ratio in adults.

\section{Conclusion}

Unlike other countries, China has a tough and much-criticized policy to control its population growth. It is the national law that most couple in China can have only one child. This policy was effectively executed: total fertility has dropped from 4.86 in 1970 s to 1.70 in the 21 st century [10]. Meanwhile, the world's total fertility is 2.65 and that of developed countries is 1.56. Not intending to address all the controversies around this policy, we attempt to describe the population profiles under this policy and the related sex-ratio imbalance in newborns.

We found that this sex-ratio imbalance will decrease the population growth when the birth rate is fixed, although this negative effort can be balanced by increasing the birth rate. There will be an abnormally large number of male individuals without female partners during their sexually active stages in the next several decades if the sex-ratio imbalance in newborns is not reduced. The sexual demands from these surplus men may increase the highrisk heterosexual or homosexual activities and thereafter increase HIV/AIDS and other STD/STI incidences. The 
Table I: Parameters estimated from Statistics China [27].

\begin{tabular}{|c|c|c|c|c|}
\hline Parameter & Description & Value & Unit & Estimation description \\
\hline$\mu$ & Birth rate & 0.11584 & Proportion & Estimated using LSE \\
\hline$\sigma$ & Males in newborns & 0.5487 & Proportion & Average ratio of age $0-4$ in $2003-2007$ \\
\hline$g_{M_{1}}, g_{F_{1}}$ & Growth rate of age group I & $1 / 15$ & Proportion & Inverse of time in age group I \\
\hline \multirow{3}{*}{$\begin{array}{l}g_{M_{2}}, g_{F_{2}} \\
d_{M_{1}} \\
d_{F_{1}}\end{array}$} & Growth rate of age group 2 & $1 / 35$ & Proportion & Inverse of time in age group 2 \\
\hline & Death rate of male in age group I & 0.00122 & Proportion & Average rate in $2003-2007$ \\
\hline & Death rate of female in age group I & 0.00122 & Proportion & Average rate in $2003-2007$ \\
\hline$d_{M_{2}}$ & Death rate of male in age group 2 & 0.0022 & Proportion & Average rate in $2003-2007$ \\
\hline$d_{F_{2}}$ & Death rate of female in age group 2 & 0.0012 & Proportion & Average rate in $2003-2007$ \\
\hline$d_{M_{3}}^{T_{2}}$ & Death rate of male in age group 3 & 0.0242 & Proportion & Average rate in $2003-2007$ \\
\hline \multirow{2}{*}{$d_{F_{3}}^{M_{3}}$} & Death rate of female in age group 3 & 0.0189 & Proportion & Average rate in $2003-2007$ \\
\hline & MVP & 0.05 & $10^{4}$ individuals & Source: [48] \\
\hline K & Carrying capacity parameter & 549186 & $10^{4}$ individuals & Estimated using LSE \\
\hline$M_{1}$ & Males in age group I & | 4072.82 & $10^{4}$ individuals & Initial population in 2003 \\
\hline$F_{1}$ & Females in age group I & 12211.95 & $10^{4}$ individuals & Initial population in 2003 \\
\hline$M_{2}$ & Males in age group 2 & 37333.68 & $10^{4}$ individuals & Initial population in 2003 \\
\hline$F_{2}$ & Females in age group 2 & 36286.94 & $10^{4}$ individuals & Initial population in 2003 \\
\hline$M_{3}$ & Males in age group 3 & | 4563.88 & $10^{4}$ individuals & Initial population in 2003 \\
\hline$F_{3}$ & Females in age group 3 & 14744.8 & $10^{4}$ individuals & Initial population in 2003 \\
\hline
\end{tabular}

impact of these surplus males on STD incidence should therefore be addressed urgently.
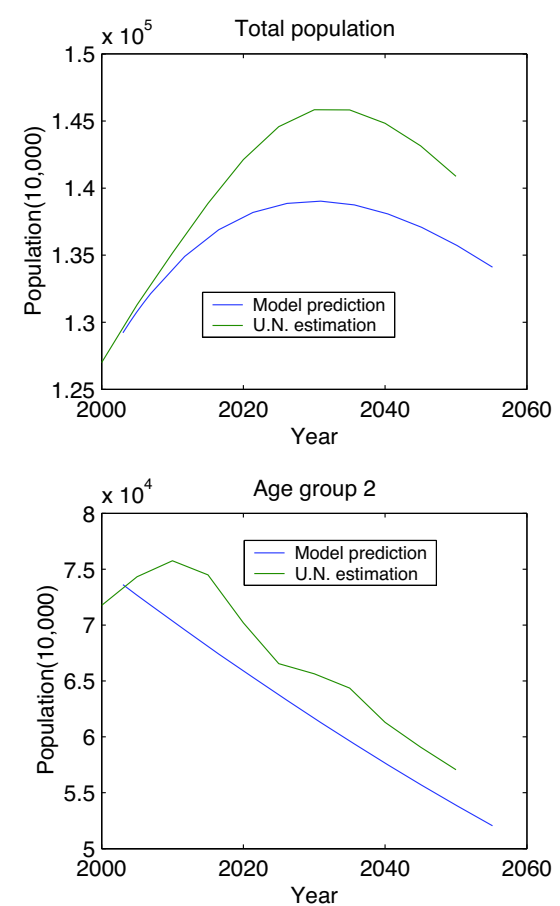

There are also other interesting sociological and psychological issues arising from the shortage of women. Discrimination against women may be undermined [43]; bride trading was reported [44]; polyandry may be nor-
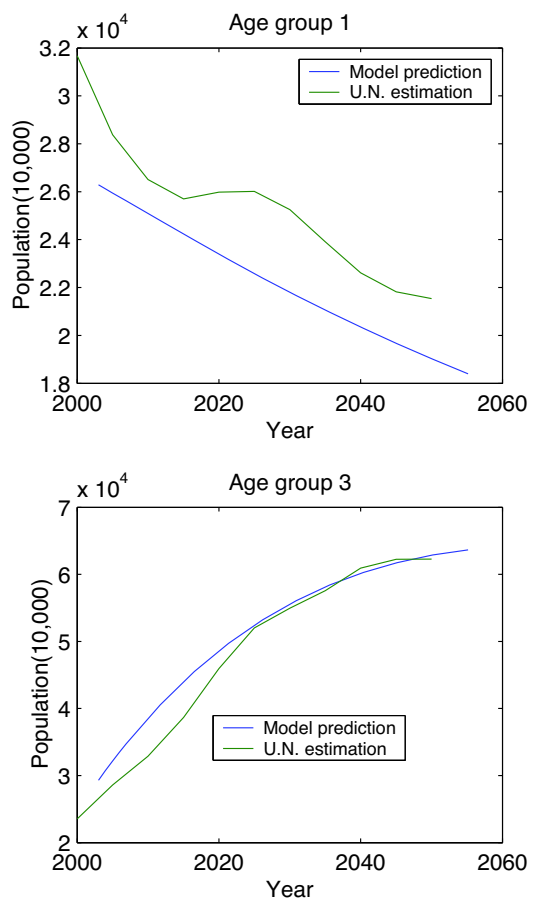

Figure 3

Model estimation v.s. U.N. by population density in each age groups. 

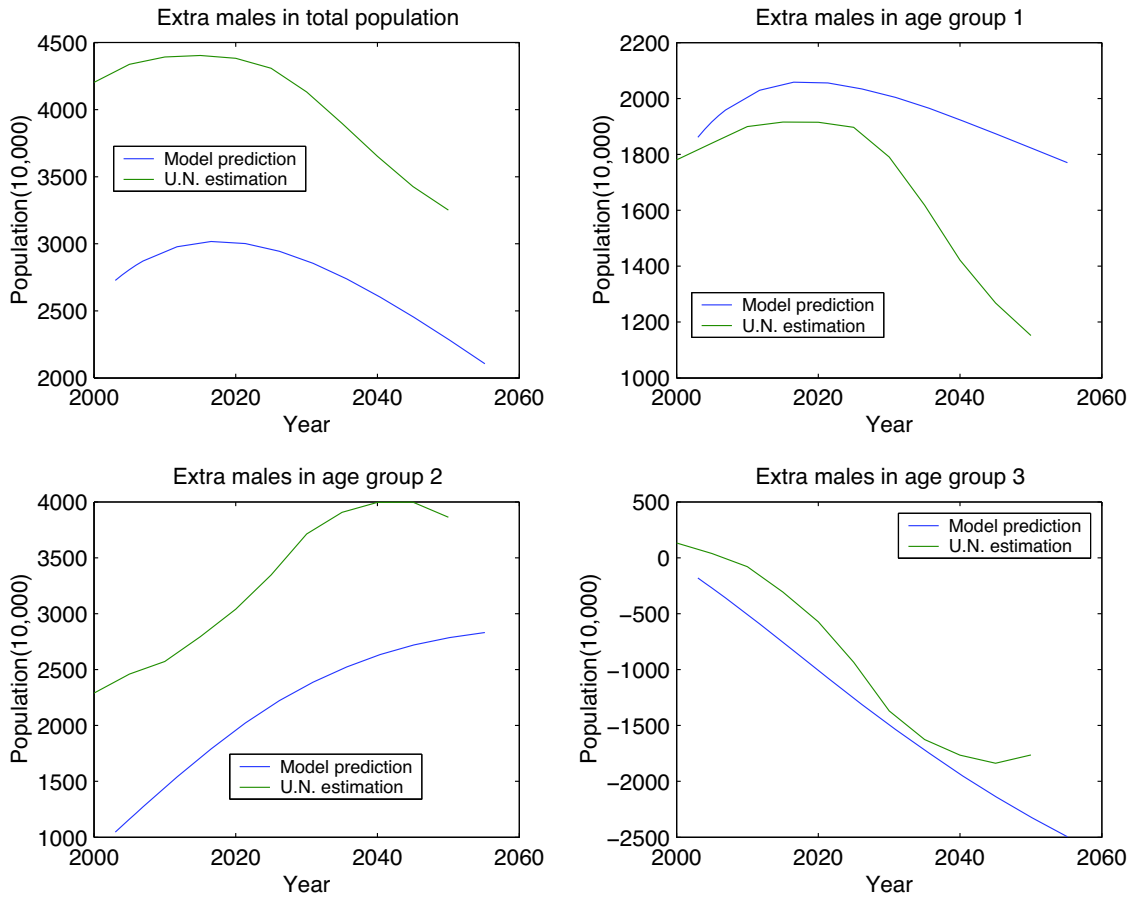

Figure 4

Model estimation v.s. U.N. by number of extra males in each age group.
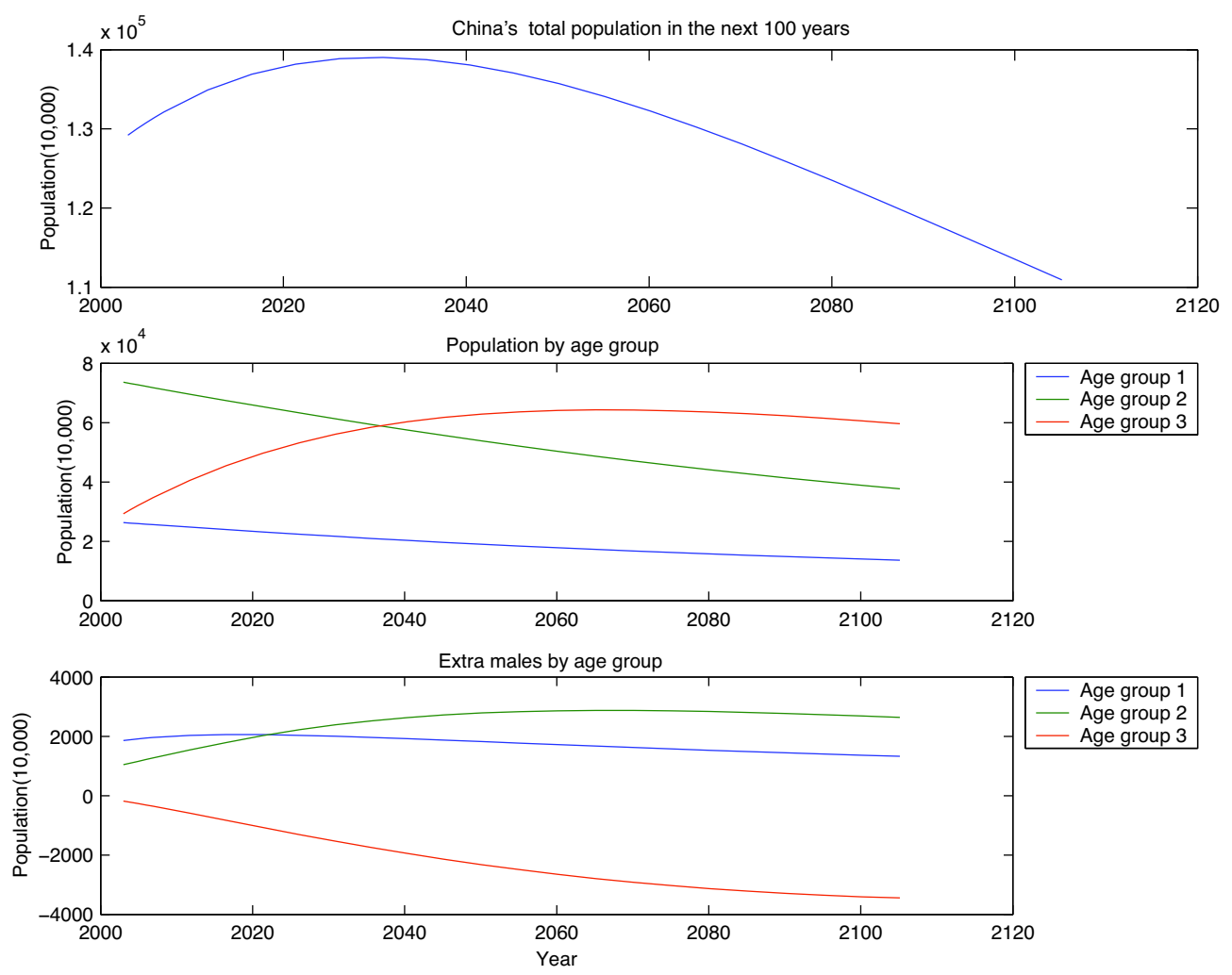

Figure 5

China's population in 100 years. 

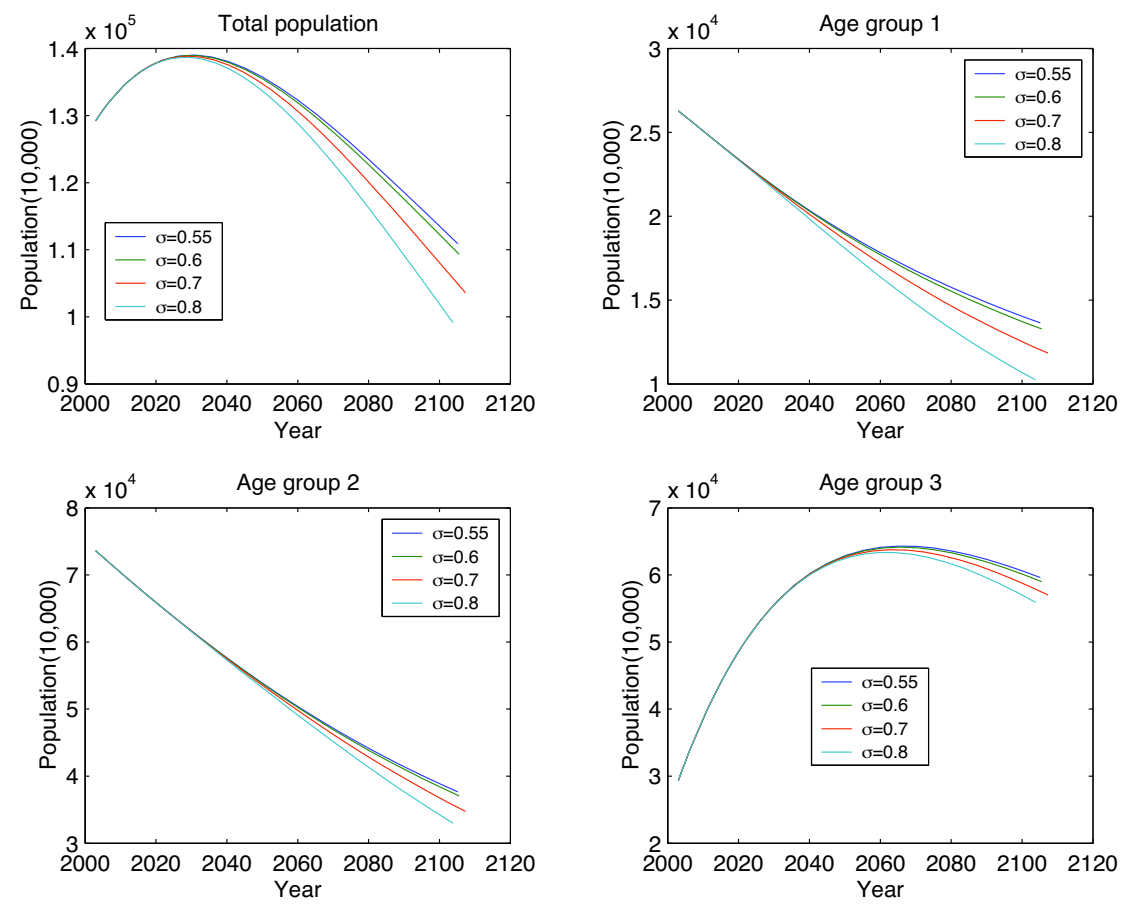

\section{Figure 6}

\section{Long-term effect to age group by varying $\sigma$.}
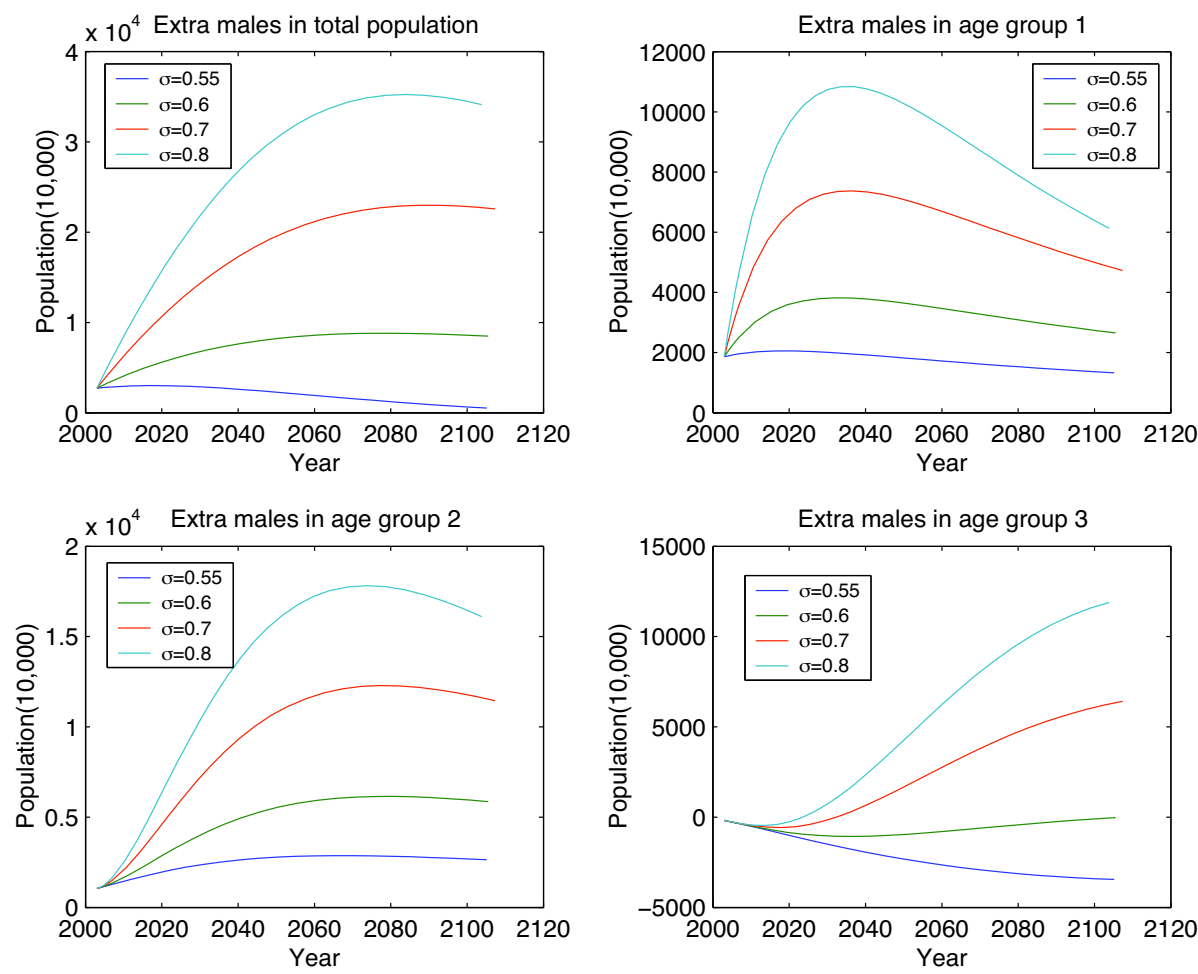

Figure 7

Long-term effect to the number of extra males by varying $\sigma$. 

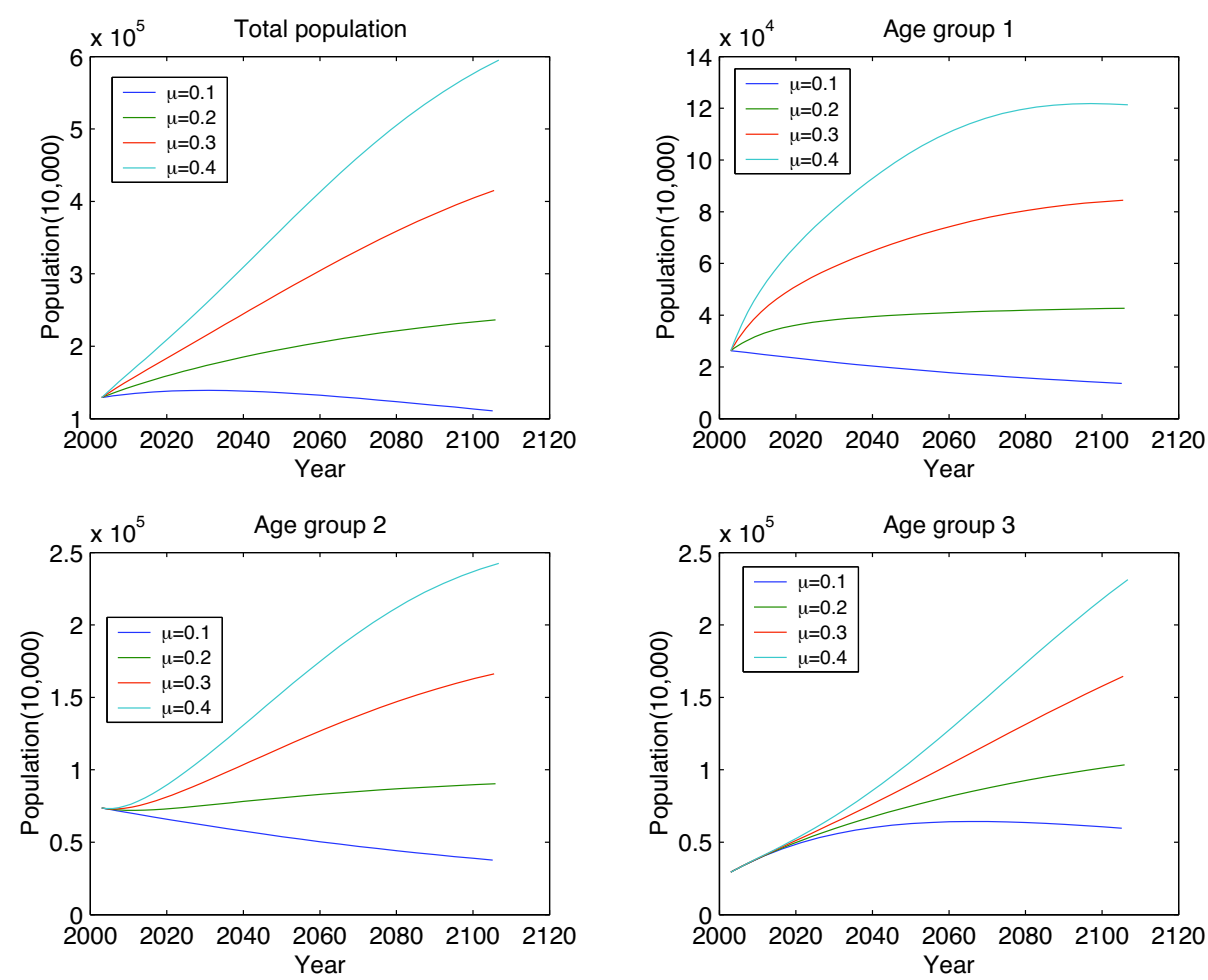

\section{Figure 8}

Long-term effect to age group by varying $\mu$.
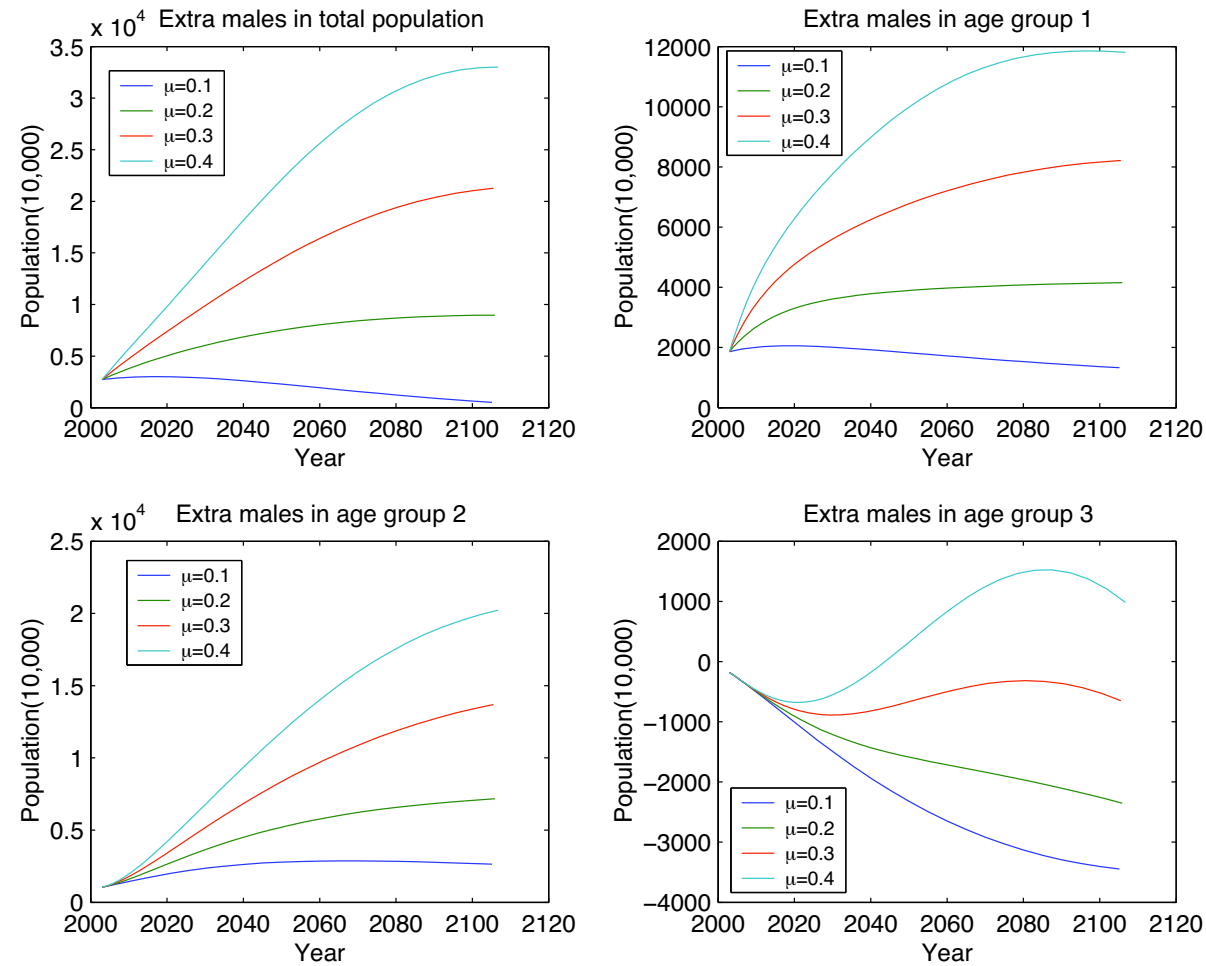

Figure 9

Long-term effect to the number of extra males by varying $\mu$. 
malized [45]; crimes against women such as rape may rise [46], although some researchers claim that rape against women may decline because of the booming sex industry [47]. More efforts are required to examine each of these issues.

\section{Competing interests}

The authors declare that they have no competing interests.

\section{Authors' contributions}

Both authors contributed to the formulation of mathematical models. YP designed and conducted the modelbased simulations and the estimation of model parameters from the literature.

\section{Acknowledgements}

This work was partially supported by Mathematics for Information Technology and omplex Systems (MITACS), by Natural Sciences and Engineering Research Council of Canada (NSERC), and by the Canada Research Chairs (CRC) Program.

This article has been published as part of BMC Public Health Volume 9 Supplement I, 2009: The OptAIDS project: towards global halting of HIVIAIDS. The full contents of the supplement are available online at http:// www.biomedcentral.com/I47I-2458/9? issue $=$ SI.

\section{References}

I. AP: China Says Argentine Died of AIDS. Tech rep, New York Times; 1985.

2. China W UNAIDS: 2005 Update on the HIVIAIDS Epidemic and Response in China 2006 [Http://data.unaids.org/publications/ExternalDocuments/rp 2005chinaestimation 25jan06 en.pdf]. Beijing, China: China CDC

3. NIC: The Next Wave of HIVIAIDS: Nigeria, Ethiopia, Russia, India, and China 2002 [Http://www.dni.gov/nic/PDF GIF otherprod/HIVAIDS/ ICA HIVAIDS20092302.pdf]. Washington, US: National Intelligence Council

4. Tucker J, Henderson G, Wang T, Huang Y, Parish W, Pan S, Chen X, Cohen M: Surplus men, sex work, and the spread of HIV in China. AIDS 2005, 19:539-547.

5. Anderson R, May RM: Infectious diseases of humans: Dynamics and control Oxford: Oxford University Press; 1992.

6. May R, Anderson R: Transmission dynamics of HIV infection. Nature 1987, 326:137-142.

7. Garnett GP, Aral SO, Hoyle DV, WC Jr, Anderson RM: The natural history of syphilis. Implications for the transmission dynamics and control of infection. Sexually transmitted diseases 1997, 24(4): $185-200$.

8. Hethcote HW, Yorke JA: Gonorrhea Transmission Dynamics and Control Volume 56. Springer; 1984. [Lecture Notes in Biomathematics].

9. Turner KM, Adams EJ, Gay N, Ghani AC, Mercer C, Edmunds WJ: Developing a realistic sexual network model of chlamydia transmission in Britain. Theoretical biology and medical modelling 2006, 3:3.

10. UNDESA: World Population Prospects: The 2006 Revision and World Urbanization Prospects: The 2005 Revision 2007 [Http:/lesa.un.org/ unpp/index.asp?panel=2]. United Nations

II. Hesketh T, Zhu W: Abnormal sex ratios in human populations: Causes and consequences. The Proceedings of the National Academy of Sciences Online (US) 2006, I 03(36): I 327I-5.

12. Senn TE, Carey MP, Vanable PA, Urban MA, Sliwinski MJ: The Maleto-Female Ratio and Multiple Sexual Partners: Multilevel Analysis with Patients from an STD Clinic. AIDS and Behavior 2008.

13. Ebenstein AY, Jennings E: Gender Policy and HIV in China Springer chap. 'Bare Branches', Prostitution, and HIV in China: A Demographic Analysis; 2008.
14. Wang B, Li X, Stanton B, Fang X, Lin D, Mao R: CHINA: HIVRelated Risk Behavior and History of Sexually Transmitted Diseases Among Male Migrants Who Patronize Commercial Sex in China. Sexually Transmitted Diseases 2007, 34:I-8.

15. Zhao R, Gao H, Shi X, Tucker JD, Yang Z, Min X, Qian H, Duan Q, Wang N: Sexually Transmitted Disease/HIV and Heterosexual Risk Among Miners in Townships of Yunnan Province, China. AIDS Patient Care and STDs 2005, I 9(1 2):848-852.

16. Parish WL, Laumann E, Cohen MS, Pan S, Zheng H, Hoffman I, Wwang T, NG KH: Population-based study of chlamydial infection in China: a hidden epidemic. the journal of the American Medical Association 2003, 289( I 0): I 265-I 273.

17. Pirkle C, Soundardjee R, Stella A: Female Sex Workers in China: Vectors of Disease? Sexually Transmitted Diseases 2007, 34(9):695-703.

18. Eigenberg HM: Homosexuality in Male Prisons: Demonstrating the Need for a Social Constructionist Approach. Criminal Justice Review 1992, 17(2):219-234.

19. Jones FD, Koshes RJ: Homosexuality and the military. the American Journal of Psychiatry 1995, I 52:16-2I.

20. Zhang BC, Chu QS: MSM and HIVIAIDS in China. Cell Research 2005, 15:858-864.

21. UN: Demographic Yearbook New York: United Nations; 1952

22. UNDIESA: Demographic Yearbook New York: United Nations; 1986.

23. Shen J, Spence N: Modelling urban-rural population growth in China. Environment And Planning A 1996, 28(8):1417-44.

24. Shen J, Spence N: Modelling regional population growth in China. Mathematical Population Studies 1997, 6(3):24I-74.

25. Shen J: China's Future Population and Development Challenges. The Geographical Journal 1998, 164:32-40.

26. Zhang L, liang Z: Analyzing the prospect of population development in China. Chinese Journal Of Population Science 1996, 8: I-I I.

27. NBSC: Statistical yearbook 2007 [Http://www.stats.gov.cn/english/sta tisticaldata/yearlydata/]. China Statistical Press

28. Becker G: An Economic Analysis of Fertility. Demographic and Economic Changes in Developed Countries 1960:209-231.

29. Becker G, Lewis H: On the Interaction between the Quantity and Quality of Children. Journal of Political Economy 1973, 81 (2S279-88 [http://ideas.repec.org/a/ucp/jpolec/v8ly 1973i2ps279. 88.html].

30. Malthus T: An Essay on the Principle of Population 1798 [http:// ideas.repec.org/b/hay/hetboo/malthus 1798 .html]. No. malthus / 798 in History of Economic Thought Books, McMaster University Archive for the History of Economic Thought

31. Agency $\mathrm{XN}$ : The beginning and development of China's Planned-Birth-policy (Translated). News 2002.

32. SCPC P: Provincial planned-birth-policies(Translated). Web 2003 [Http://www.china.com.cn/zhuanti2005/node 5457646.htm].

33. Chahnazarian A: Determinants of the sex ratio at birth: Review of recent literature. Social Biology 1988, 35:2 I4-235.

34. Li N, Feldmanc MW, Li S: Cultural Transmission in a Demographic Study of Sex Ratio at Birth in China's Future. Theoretical Population Biology 2000, 58:161-172 [Http://www.china.com.cn/ zhuanti2005/node 5457646.htm]

35. Li N, Feldmanc MW, Tuljapurkar S: Sex ratio at birth and son preference. Mathematical Population Studies 1999, 8:91-107.

36. Poston DL: Son preference and fertility in China. Journal of Biosocial Science 2002, 34:333-347.

37. Yellin J, Samuelson PA: A Dynamical Model for Human Population. The Proceedings of the National Academy of Sciences of the United State of America 1974, 7 I (2):2813-17.

38. Shaffer ML: Minimum Population Sizes for Species Conservation. BioScience 198I, 31 (2): $131-134$.

39. Gilpin ME, Soule ME: Minimum viable populations: The processes of species extinctions Sunderland Mass: Sinauer Associates chap. Conservation biology: The science of scarcity and diversity; 1986:13-34.

40. Soule ME, (Ed): Viable Populations for Conservation Cambridge University Press; 1987.

4I. Daily GC, Ehrlich PR: Population, Sustainability, and Earth's Carrying Capacity. BioScience 1992, 42(10):76I-771.

42. Cao M, Ma S, Han C: Potential Productivity and Human Carrying Capacity of an Agro-Ecosystem: An Analysis of Food Production Potential of China. Agricultural Systems 1995, 47(4):387-4I4.

43. Kim D: Missing girls in South Korea: Trends, levels and regional variations. Population-English 2004, 59(6):865-878. 
44. Sharma V: Declining sex ratio forces import of brides. News, The Hindu; 2008.

45. Mann K: Tribal women: on the threshold of Twenty-first century M.D. Publications Pvt. Ltd; 1996.

46. Sharma V: Crime against women on the rise in Punjab, Haryana. News, The Hindu; 2009.

47. Cundiff KR: Prostitution and Sex Crimes. Issue 50 the Independent Institute; 2004.

48. Franklin IR: Conservation Biology: An Evolutionary-Ecological Perspective Sinauer Associates, Sunderland, MA, U.S.A., chap. Evolutionary change in small populations; 1980: 145-149.

Publish with Bio Med Central and every scientist can read your work free of charge

"BioMed Central will be the most significant development for disseminating the results of biomedical research in our lifetime. "

Sir Paul Nurse, Cancer Research UK

Your research papers will be:

- available free of charge to the entire biomedical community

- peer reviewed and published immediately upon acceptance

- cited in PubMed and archived on PubMed Central

- yours - you keep the copyright

Submit your manuscript here:

http://www.biomedcentral.com/info/publishing_adv.asp
BioMedcentral 